\title{
Proteomic and Electron Microscopy Study of Bacteriophages From Bartonella Henselae And Bartonella Grahamii
}

Nahálková J ${ }^{* 1,2}$, Nielsen $\mathrm{ML}^{3,4}$

${ }^{1}$ Department of Medical Biochemistry and Microbiology (IMBIM), BMC, Uppsala University, Husargatan 3, SE-75124 Uppsala, Sweden.

${ }^{2}$ Molecular Evolution, Department of Evolution, Genomics and Systematics, Uppsala University, Norbyvägen 18C, SE-752 36 Uppsala, Sweden.

${ }^{3}$ The Novo Nordisk Foundation Center for Protein Research, Panum Institute, Blegdamsvej 3, DK-2200 Copenhagen, Denmark.

${ }^{4}$ Department of Cell and Molecular Biology, BMC, Uppsala University, Husargatan 3, SE-751 24 Uppsala, Sweden.

\begin{abstract}
Bacteriophages are one of the key factors playing an important role in exchange of genetic information between different bacterial species leading towards bacterial evolution. Their study becomes especially significant if bacteriophages contribute to the development of new human pathogens. In the present study we have investigated the occurence of bacteriophages in Bartonella, a genus of Gram-negative bacteria representing facultative intracellular parasites causing strong infections mainly in immune-compromised patients. Proteomic and morphologic characterization of bacteriophage preparations from B. henselae and B. grahamii bacteriophages indicated the presence of three different types of bacteriophages. Bacteriophage-like particles with diameter $42 \mathrm{~nm}$, non-enveloped tailed bacteriophages and large enveloped phages with icosahedral to round cores were identified. Most of the results of our observations suggests, that B. henselae is the host of tailed dsDNA bacteriophages belonging to order Caudovirales and family Myoviridae (similar to bacteriophage P2), and enveloped bacteriophages similar to dsRNA viruses from family Cystoviridae. Small size bacteriophage-like particles could correspond to defective or satellite phages. Similar conclusions might be drawn for B. grahamii, though less experimental evidences are available.
\end{abstract}

Keywords: Rochalimaea, Cat Scratch Disease, Zoonotic Disease, Evolution of Pathogenic Bacteria, Horizontal Gene Transfer

\section{*Corresponding Author:}

Jarmila Nahálková,

Molecular Evolution, Department of Evolution, Genomics and Systematics, Uppsala University, Norbyvägen 18C, SE-752 36 Uppsala, Sweden. Tel: +46737707700

E-mail: jarmila.nahalkova@gmail.com

Received: September 25, 2014

Accepted: November 03, 2014

Published: November 06, 2014

Citation: Nahálková J, Nielsen ML (2014) Proteomic and Electron Microscopy Study of bacteriophages From Bartonella Henselae And Bartonella Grahamii. Int J Virol Stud Res, 2(1), 1-7. doi: http://dx.doi. org/10.19070/2330-0027-140001

Copyright: Nahálková $\mathbf{J}^{\odot}$ 2014. This is an open-access article distributed under the terms of the Creative Commons Attribution License, which permits unrestricted use, distribution and reproduction in any medium, provided the original author and source are credited.

\section{Introduction}

Bartonella (known also as Rochalimaea) is a genus of Gram-negative bacteria representing facultative intracellular parasites. These bacteria can on occasion infect healthy people, but are considered as opportunistic pathogens causing strong infections in immunecompromised patients such as those with AIDS.

Bartonella-s are transmitted by blood sucking arthropods, e.g. ticks, fleas, sand flies and mosquitoes. They use zoonotic reservoir for their transfer to human. After their invasion of primary niche endothelial cells of reservoir animal, they are released in period intervals to bloodstream, where they invade erythrocytes. Bacterial infection might be transferred to human through occasional scratch by infected animal.

Bartonella henselae is a zoonotic pathogen using cats as a reservoir and causing cat scratch disease (CSD) [1]. The disease has serious symptoms characterized by lymphadenopathy and persistent fever. It might have even more severe symptoms in AIDS patients, where it can cause bacillary angiomatosis, bacillary peliosis hepatis, endocarditis and bacteremia associated with relapsed fever [2]. $B$. henselae has been identified as a one of eyes infecting bacterial species occurring with increasing incidence [3,4]. Another species involved in intraocular inflammatory disease is Bartonella grahamii, which uses rodents as a reservoir [5]. Infection in this case triggers even behavioural changes in patients [6].

Bacteriophages are one of the key elements playing an important role in acquisition of new genetic information by various bacterial species leading towards evolution of bacteria [7]. Bacterial survival and adaptation to new environmental conditions and host species are likewise mediated by bacteriophages. Furthermore, they might enhance bacterial evasion or inactivation of host defense mechanisms. In addition, bacteriophage genomes often contain a variety of genes horizontally transferred to various bacteria by phage infection. Importance of our knowledge concerning bacteriophages increases, if they are carrier of genes encoding virulence factors. Phage infection raises virulence of the bacteria and 
sometimes converts a non-pathogenic strain to a dangerous pathogen [8]. Thus, questions regarding evolution of bacteriophages, acquiring of new genes, their diversification and horizontal transfer between bacterial species are one of the issues with biological and medical relevance.

Several authors have demonstrated the occurrence of bacteriophage-like particles amongst Bartonella-s $[9,10,11,12]$. The particles conserved among different Bartonella species are capable to package host DNA and export it outside of host cells. It suggests possible role of these bacteriophage particles in genetic exchange [13].

The present study confirmed the occurrence of before reported bacteriophage particles in both B. henselae and B. grahamii with diameter approximately $40 \mathrm{~nm}$ and with similar morphology and relative molecular weights of three main bacteriophage proteins. Furthermore, large enveloped and non-enveloped tailed bacteriophages were found in both cultures as well. To characterize structural bacteriophage proteins, we have performed sensitive proteomic analysis and identified bacteriophage-associated proteins.

\section{Materials and Methods}

\section{Growth of Bacterial Strains}

B. henselae Houston-1 and B. grahamii were routinely grown for 5-10 days on blood agar containing $5 \%(\mathrm{v} / \mathrm{v})$ horse blood (CSB agar; Statens veterinärmedicinska anstalt (SVA), Uppsala, Sweden) in a humidified atmosphere with $5 \%(\mathrm{v} / \mathrm{v}) \mathrm{CO}_{2}$ at $35^{\circ} \mathrm{C}$.

\section{Isolation of Bacteriophages}

The isolation procedure was adopted from Anderson et al. (1994) [10] with a few additional modifications. Bacteria were scraped from agar plates and immediately transferred into sterile Dulbecco's phosphate buffered saline (DPBS; pH 7,2). Bacterial biomass obtained by growth on each plate was collected by addition of $0,5 \mathrm{ml}$ of DPBS. Bacteria were pelleted by twice repeated centrifugation for $1 \mathrm{~min}$ at $10000 \times \mathrm{g}$. The supernatant after second centrifugation was collected and bacteriophages were precipitated by addition of the solution consisted of $20 \%(\mathrm{w} / \mathrm{v})$ PEG 8000 and 2,5 M NaCl. The mixture was incubated overnight at $4^{\circ} \mathrm{C}$. Bacteriophage pellet was collected by centrifugation at 10 $000 \times \mathrm{g}$ for $10 \mathrm{~min}$. Then particles were suspended in sterile SM buffer [14] and left for a few hours on ice before complete resuspension. The bacteriophage suspension was further stored at $4^{\circ} \mathrm{C}$.

\section{SDS-PAGE}

Bacteriophage suspension was solubilized in NuPAGE ${ }^{\circledR}$ LDS $4 \times$ LDS sample buffer (Invitrogen AB, Sweden), cleaned-up using ProteoExtract ${ }^{\mathrm{TM}}$ Protein Precipitation Kit (Calbiochem, Merck4Biosciences, Sweden) and solubilized again in NuPAGE ${ }^{\circledR}$ LDS $4 \times$ LDS sample buffer. Sample was run at reducing conditions on 4-12 \% NuPAGE Bis-Tris Gel using MOPS running buffer. The gels were stained by Bio-Safe Coomassie Stain (Biorad, Sweden), individual lanes cut off and used for proteomic analysis

\section{Proteomic Analysis}

Excised polyacrylamide slices have been further reduced, alkylated and in-gel digested by trypsin [15]. Nanoflow LC-MS/MS analysis was performed on a 7-tesla hybrid linear iontrap (LTQ) FT mass spectrometer (Thermo Electron, Bremen, Germany) modified with a nanoelectrospray ion source (Proxeon Biosystems, Odense, Denmark) according to the protocol of Nielsen et al (2005) [16]. Protein and peptides were identified by searching of tandem mass spectra using Mascot search engine against the non-redundant NCBI protein database. Analysis was performed twice and only statistically significant Mascot matches with individual ion scores indicating identity or extensive homology above cut off score for $95 \%$ of correctly assigned peptides $(\mathrm{p} \leq 0.05)$ and at the same time existing in both analyses were selected. Only proteins identified by minimum two peptides were included in the study and the proteins assigned through single peptide matches were excluded from further analysis.

\section{Transmission Electron Microscopy}

Sample preparation was performed according to the protocol of Barbian and Minnick (2000) [11]. Bacteriophage suspension was deposited on Silicon Monoxide Type-A support grids (300 mesh copper) and stained by $1 \%(\mathrm{w} / \mathrm{v})$ sodium phosphotungstate. The grids were observed under Zeiss Supra 35VP electron microscope.

\section{Results}

To investigate occurrence of bacteriophages in the cultures of B. henselae (BH) Houston-1 and B. grahamii (BG), bacteriophages have been isolated from in vitro cultured bacteria. These preparations have been characterized by both morphologic and proteomic analysis.

\section{Size and Morphology of Bacteriophage-like Particles in $B$. Henselae and B. Grahamii}

In the current study, the electron microscopy images showed the presence of icosahedral particles in two ranges of sizes. In both $\mathrm{BH}$ and $\mathrm{BG}$ bacteriophage preparations, icosahedral particles having average diameter between opposite vertices equal to 42 $\mathrm{nm}$ were present (Fig. $1 \mathrm{~A}$ ). The average value of the diameters between opposite faces was $36 \mathrm{~nm}$ (Fig. 1 A). Furthermore, in both bacterial cultures there were also observed larger enveloped bacteriophages with icosahedral to round shaped core (Fig. 1 B, C, D) and tailed bacteriophages (data not shown). Both detected enveloped and non-enveloped phages were larger in their diameters than before described $40 \mathrm{~nm}$ particles. The diameter of enveloped particles varied between 110-160 nm, while cores of enveloped particles had diameters in range between $88-110 \mathrm{~nm}$. The tailed phages consisted of a capsid with average diameter $87 \mathrm{~nm}$; tail and fibers were about $175 \mathrm{~nm}$ and $83 \mathrm{~nm}$ long.

\section{Protein Analysis of B. Henselae and B. Grahamii Bacterio- phages}

SDS-PAGE analysis of BH bacteriophages showed several protein bands with following relative molecular weights: $21 ; 27 ; 30$; 32; 42; 46 and $63 \mathrm{kDa}$, where major bands had $\mathrm{Mr}$ equal to 32; 46 and $63 \mathrm{kDa}$. Following values relative molecular weights of protein bands were detected by analysis of BG bacteriophage preparations: $14 ; 19 ; 25 ; 27 ; 30 ; 32 ; 33 ; 36 ; 37 ; 42 ; 45 ; 51 ; 60$ and $63 \mathrm{kDa}$.

Further proteomic analysis using LC-MS/MS assisted in identification of several of these proteins and also included other 
low-abundant proteins phage proteins. Results of this analysis including information concerning their potential functions are summarized in both Table 1 and Table 2.
In our present study, bacteriophages of different types were detected by electron microscopy in the bacteriophage suspensions prepared from cultures of both $\mathrm{BH}$ and BG. By morphologic analysis we have identified before described bacteriophage-like particles, non-enveloped tailed and novel enveloped bacteriophages. The proteomic analysis of structural phage proteins has

\section{Discussion}

Figure1. Bacteriophages isolated from cultures of facultative intracellular parasites Bartonella grahamii and henselae.
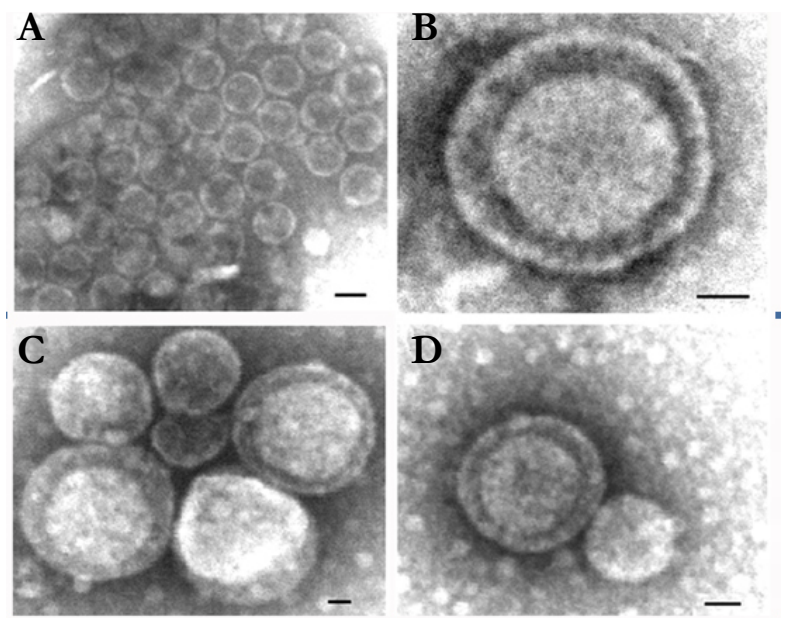

Electron microscopy of B. grahamii (A, B) and B. henselae (C, D) bacteriophages prepared by differential centrifugation followed by precipitation using $20 \%$ (w/v) PEG/2.5 M NaCl. Bacteriophage suspension was deposited on Silicon Monoxide Type-A support grids and stained by $1 \%(\mathrm{w} / \mathrm{v})$ sodium phosphotungstate. Bacteriophage-like particles from B. grahamii (A) and large enveloped bacteriophages occuring in both B. grahamii (B) and B. henselae were observed (C, D) under Zeiss Supra 35VP electron microscope.

Scale bars: $30 \mathrm{~nm}$

Table 1. The list of proteins identified by LC-MS/MS analysis of bacteriophage preparations from B. henselae. The proteins were identified by minimum two peptide matches and using statistically significant Mascot scores above threshold indicating $95 \%$ correctly assigned peptides $(\mathrm{p} \leq 0.05)$. Minimum Mascot score value of matches used in this study was 63 .

\begin{tabular}{|c|c|c|c|c|c|}
\hline Protein name & $\begin{array}{l}\text { NCBI } \\
\text { Accession } \\
\text { number }\end{array}$ & $\begin{array}{l}\text { Protein } \\
\text { mass/aa }\end{array}$ & Motifs/E-value & Function & $\begin{array}{l}\text { Other homologs/Acces- } \\
\text { sion number/E-value }\end{array}$ \\
\hline Phage tail protein & CAF27115 & $8179 / 74$ & $\begin{array}{l}\text { cl02088, Phage_- } \\
\text { tail_X super family, } \\
\text { Phage Tail Protein } \\
\text { X/4.14e-17 }\end{array}$ & P2-like phage tail protein & $\begin{array}{l}\text { Phage tail protein } \\
\text { [Bartonella tribocorum }] / \\
\text { YP_001608777.1/5e-45 }\end{array}$ \\
\hline $\begin{array}{l}\text { Phage protein gp } 25 \\
\text { (Baseplate assembly protein W) }\end{array}$ & CAF27129 & $12171 / 109$ & $\begin{array}{l}\text { cl01403, GPW_gp25, } \\
\text { Gene 25-like } \\
\text { lysozyme/ } 3.33 \mathrm{e}-36\end{array}$ & $\begin{array}{l}\text { Structural protein of outer } \\
\text { wedge of T4 baseplate hav- } \\
\text { ing acidic lysozyme activity }\end{array}$ & $\begin{array}{l}\text { Baseplate assembly protein } \\
\text { W [Bartonella washoensis]/ } \\
\text { WP_006925683/1e-32 }\end{array}$ \\
\hline Phage tail protein & CAF27116 & $14011 / 126$ & $\begin{array}{l}\text { pfam06995, Phage P2 } \\
\text { GpU/ 3.02e-49 }\end{array}$ & $\begin{array}{l}\text { P2 GpU protein probably } \\
\text { involved in tail assembly }\end{array}$ & $\begin{array}{l}\text { Tail formation protein, } \\
\text { phage P2 GpU [Pseu- } \\
\text { domonas fluorescens A506]/ } \\
\text { YP_006323125/1e-57 }\end{array}$ \\
\hline Phage-related protein & CAF27181 & $14389 / 127$ & $\begin{array}{l}\text { cd03352, UDP-3-O- } \\
\text { acyl-glucosamine } \\
\text { N-acyltransferase } \\
(\text { LpxD)/ } \\
2.85 \mathrm{E}-4\end{array}$ & $\begin{array}{l}\text { Lipid A biosynthetic pathway } \\
\text { in Gram-negative bacteria }\end{array}$ & $\begin{array}{l}\text { UDP-3-O-[3-hydroxymyris- } \\
\text { toyl] glucosamine N-acyl- } \\
\text { transferase [Mannheimia suc- } \\
\text { ciniciproducens MBEL55E]/ } \\
\text { YP_089114.1/ 2e-24 }\end{array}$ \\
\hline Single-strand binding protein & CAF27165 & $16780 / 148$ & $\begin{array}{l}\text { [COG0629], Single- } \\
\text { stranded DNA-binding } \\
\text { protein } / 4.12 \mathrm{e}-37\end{array}$ & $\begin{array}{l}\text { DNA replication, recombi- } \\
\text { nation, and repair }\end{array}$ & $\begin{array}{l}\text { Single-strand binding } \\
\text { protein (ssb) [Bartonella } \\
\text { tribocorum CIP 105476]/ } \\
\text { YP_001609352.1/1e-92 }\end{array}$ \\
\hline Major tail tube protein FII & YP_033153 & $18614 / 168$ & $\begin{array}{l}\text { pfam } 04985 \text {, Phage } \\
\text { tail tube protein } \\
\text { FII } / 3.08 \mathrm{e}-68\end{array}$ & Phage tail & $\begin{array}{l}\text { Phage tail tube pro- } \\
\text { tein [Bartonella tribo- } \\
\text { corum CIP 105476]/ } \\
\text { YP_001608942.1/7e-118 }\end{array}$ \\
\hline Phage protein & CAF27122 & $19607 / 173$ & $\begin{array}{l}\text { cl10713, Phage pRha, } \\
\text { Phage regulatory pro- } \\
\text { tein Rha/ } 7.13 \mathrm{e}-20\end{array}$ & $\begin{array}{l}\text { Probable inhibition of bacte- } \\
\text { rial host transcription }\end{array}$ & $\begin{array}{l}\text { Phage protein [Bar- } \\
\text { tonella sp. AR 15-3]/ } \\
\text { CBI79586.1/5e-114 }\end{array}$ \\
\hline Anti-repressor protein & CAF27155 & $19738 / 171$ & $\begin{array}{l}\text { [pfam08346], } \\
\text { AntA/AntB } \\
\text { antirepressor/3.07e-35 }\end{array}$ & Bacteriophage anti-repressor & $\begin{array}{l}\text { Anti-repressor pro- } \\
\text { tein [Bartonella triboco- } \\
\text { rum CIP 105476] / } \\
\text { YP_001608925.1/6e-64 }\end{array}$ \\
\hline
\end{tabular}




\begin{tabular}{|c|c|c|c|c|c|}
\hline Anti-repressor protein & YP_033189 & $20697 / 180$ & $\begin{array}{l}\text { [pfam08346], } \\
\text { AntA/AntB } \\
\text { antirepressor/8.51E-32 }\end{array}$ & Bacteriophage anti-repressor & $\begin{array}{l}\text { anti-repressor protein } \\
{[\text { Bartonella tribocorum } \text { CIP }} \\
105476 \\
\text { YP_001608925.1/1.e-83 }\end{array}$ \\
\hline Phage-related protein & CAF27489 & $21141 / 259$ & $\begin{array}{l}\text { pfam04404, ERF, ERF } \\
\text { superfamily/1.41e-20 }\end{array}$ & $\begin{array}{l}\text { DNA single-strand annealing } \\
\text { protein, DNA recombination }\end{array}$ & $\begin{array}{l}\text { Recombinase [Bar- } \\
\text { tonella taylorii]/ } \\
\text { WP_0107047847.1/2e-127 }\end{array}$ \\
\hline Phage protein gp13 & CAF27147 & $21649 / 193$ & - & $\begin{array}{l}\text { Structural protein of neck of } \\
\text { bacteriophage } \mathrm{T} 4\end{array}$ & $\begin{array}{l}\text { Phage protein [Bar- } \\
\text { tonella vinsonii]/ } \\
\text { WP_0107047847.1/2e-127 }\end{array}$ \\
\hline $\begin{array}{l}\text { Phage-related baseplate assem- } \\
\text { bly protein }\end{array}$ & CAF27130 & $24148 / 229$ & $\begin{array}{l}\text { [pfam04717], Phage-re- } \\
\text { lated baseplate assem- } \\
\text { bly protein } / 5.34 \mathrm{e}-21\end{array}$ & Phage baseplate assembly & $\begin{array}{l}\text { phage-related base- } \\
\text { plate assembly protein } \\
\text { [Bartonella sp. } 1-1 \mathrm{C}] / \\
\text { CBI80300.1/2e-140 }\end{array}$ \\
\hline Phage related lysozyme & YP_033722 & $24505 / 221$ & $\begin{array}{l}\text { cd00737, endolysin, } \\
\text { autolysin } / 2 \mathrm{e}-40\end{array}$ & $\begin{array}{l}\text { Enzyme of dsDNA phages } \\
\text { hydrolysing beta-1,4-linked } \\
\text { polysaccharides involved in } \\
\text { bacterial cell wall }\end{array}$ & $\begin{array}{l}\text { Lysozyme [Bar- } \\
\text { tonella sp. DB5-6]/ } \\
\text { WP_007552512.1/9e-135 }\end{array}$ \\
\hline Anti-repressor protein & CAF27154 & $28812 / 252$ & $\begin{array}{l}\text { cl01430, Ant A, AntA/ } \\
\text { AntB antirepressor/ } \\
1.61 \mathrm{e}-36\end{array}$ & Bacteriophage anti-repressor & $\begin{array}{l}\text { Antirepressor [Bartonella } \\
\text { doshiae]/WP_004856719.1/ } \\
\text { 7e-162/ }\end{array}$ \\
\hline $31 \mathrm{~K}$ major protein, Pap31 & JC6528 & $30056 / 281$ & $\begin{array}{l}\text { pfam02530, Porin_2, } \\
\text { Porin subfamily/4e-34 }\end{array}$ & $\begin{array}{l}\text { Membrane channels for } \\
\text { transport of hydrophilic } \\
\text { compounds }\end{array}$ & $\begin{array}{l}\text { Hemin binding pro- } \\
\text { tein [Bartonella vinsonii]/ } \\
\text { WP_010704727.1/ 1e-135 }\end{array}$ \\
\hline Hemin binding protein $\mathrm{c}$ & YP_031945 & $30103 / 277$ & $\begin{array}{l}\text { [COG3637], Opacity } \\
\text { protein and related sur- } \\
\text { face antigens } / 4.45 \mathrm{e}-25\end{array}$ & $\begin{array}{l}\text { Cell envelope biogenesis, } \\
\text { outer membrane }\end{array}$ & $\begin{array}{l}\text { Hemin binding protein c } \\
\text { [Bartonella quintana str. Tou- } \\
\text { louse]/ YP_031945.1/0.0 } \\
\text { Omp25/ropB family outer } \\
\text { membrane protein [Bar- } \\
\text { tonella bacilliformis KC583]/ } \\
\text { YP_989466.1/ 5e-96 }\end{array}$ \\
\hline Hemin binding protein $\mathrm{d}$ & YP_033317 & $30251 / 274$ & $\begin{array}{l}\text { [COG3637], Opacity } \\
\text { protein and related sur- } \\
\text { face antigens / } 5.42 \mathrm{e}-23\end{array}$ & $\begin{array}{l}\text { Cell envelope biogenesis, } \\
\text { outer membrane }\end{array}$ & $\begin{array}{l}\text { Hemin binding pro- } \\
\text { tein [Bartonella vinsonii } \\
\text { subsp. berkhoffii str. Winnie]/ } \\
\text { YP_007462349.1/ 1e-139 }\end{array}$ \\
\hline Phage protein gp26 & CAF27128 & $30840 / 275$ & $\begin{array}{l}\text { cl01294, Baseplate J- } \\
\text { like protein/ 1.02e-35 }\end{array}$ & $\begin{array}{l}\text { Protein located on baseplate } \\
\text { edge of bacteriophage P2, }\end{array}$ & $\begin{array}{l}\text { Phage-related baseplate } \\
\text { assembly protein [Bartonella } \\
\text { sp. } 1-1 \mathrm{C}] / \text { CBI80302.1/0.0 }\end{array}$ \\
\hline Phage protein gp20 & YP_033172 & $40117 / 358$ & $\begin{array}{l}\text { [pfam03864] Phage_- } \\
\text { cap_E/ 6.97e-87 }\end{array}$ & $\begin{array}{l}\text { Major capsid protein E of } \\
\text { the phage heads, stabilisation } \\
\text { of the condensed form of } \\
\text { the DNA molecule }\end{array}$ & $\begin{array}{l}\text { Phage protein [Bartonella } \\
\text { tribocorum CIP 105476]/0.0 }\end{array}$ \\
\hline Phage protein gp18 & CAF27143 & $40386 / 369$ & $\begin{array}{l}\text { cd07022, Signal } \\
\text { peptide peptidase A/ } \\
3.00 \mathrm{e}-90\end{array}$ & $\begin{array}{l}\text { Tail sheath protein of bac- } \\
\text { teriophage T4 }\end{array}$ & $\begin{array}{l}\text { Phage protein [Bar- } \\
\text { tonella vinsonii]/ } \\
\text { WP_010704780.1/0.0 }\end{array}$ \\
\hline Hypothetical protein & YP_034106 & $41120 / 372$ & $\begin{array}{l}\text { [pfam13252], Pro- } \\
\text { tein of unknown } \\
\text { function/1.42e-139 }\end{array}$ & $\begin{array}{l}\text { Bacterial and viral proteins } \\
\text { with uncharacterized func- } \\
\text { tion }\end{array}$ & $\begin{array}{l}\text { Phage related protein } \\
\text { [Bartonella grabamii as4 aup]/ } \\
\text { YP_002972501.1/0.0 }\end{array}$ \\
\hline Phage protein gp27 & CAF27127 & $42012 / 368$ & $\begin{array}{l}\text { cl01817, Tail_P2_I, } \\
\text { Phage tail protein } \\
\text { (Tail_P2_I) } / 3.74 \mathrm{e}-07\end{array}$ & Phage tail protein & $\begin{array}{l}\text { Phage protein [Bartonella } \\
\text { tribocorum CIP 105476]/ } \\
\text { YP_001608790.1/0.0 }\end{array}$ \\
\hline Major tail sheath protein FI & YP_033154 & $44358 / 440$ & $\begin{array}{l}\text { cl01389, Phage_- } \\
\text { sheath_1, Phage tail } \\
\text { sheath protein } / 4 \mathrm{e}-94\end{array}$ & Phage tail sheath protein & $\begin{array}{l}\text { Phage-related tail sheath } \\
\text { protein [Bartonella tri- } \\
\text { bocorum CIP 105476/ } \\
\text { YP_001608782.1/0.0 }\end{array}$ \\
\hline Hypothetical prophage protein & CAF27125 & $45034 / 368$ & $\begin{array}{l}{[\mathrm{cl} 15092], \text { Phage tail }} \\
\text { repeat like/ } 2.23 \mathrm{e}-04\end{array}$ & $\begin{array}{l}\text { Probably structural protein } \\
\text { of phage tail fibre base- } \\
\text { plate, potential function in } \\
\text { bacterial pathogenicity or } \\
\text { interactions }\end{array}$ & $\begin{array}{l}\text { Phage tail collar protein } \\
\text { [Bartonella grabamii as4aup]/ } \\
\text { YP_002971363/ 6e-117 }\end{array}$ \\
\hline Phage protein gp17 & CAF27144 & $59214 / 518$ & $\begin{array}{l}\text { [pfam05136], Phage } \\
\text { portal protein, lambda } \\
\text { family/ } 2.54 \mathrm{e}-83\end{array}$ & $\begin{array}{l}\text { Protein forming portal, } \\
\text { which enables DNA pas- } \\
\text { sage during packaging and } \\
\text { ejection. }\end{array}$ & $\begin{array}{l}\text { Phage portal protein } \\
\text { [Bartonella birtlesii]/ } \\
\text { WP_017196268.1/0.0 }\end{array}$ \\
\hline $\begin{array}{l}\text { Phage terminase large subunit } \\
\text { (gp15) }\end{array}$ & CAF27146 & $72486 / 642$ & $\begin{array}{l}\text { [pfam05876], Phage } \\
\text { terminase large subunit } \\
(\mathrm{GpA}) / 00\end{array}$ & $\begin{array}{l}\text { Site-specific binding and } \\
\text { cutting of the DNA in the } \\
\text { initial stages of packaging }\end{array}$ & $\begin{array}{l}\text { Terminase large } \\
\text { subunit [Bartonella } \\
\text { tribocorum CIP 105476]/ } \\
\text { YP_001608808/0.0 }\end{array}$ \\
\hline
\end{tabular}




\begin{tabular}{|l|l|l|l|l|}
\hline Phage tail protein & CAF27117 & $82127 / 766$ & $\begin{array}{l}\text { TIGR01760, tape_ } \\
\text { meas_TP901, phage } \\
\text { tail tape measure } \\
\text { protein, TP901 family, } \\
\text { core region/9.36e-06 }\end{array}$ & $\begin{array}{l}\text { Phage tail assembly and tail } \\
\text { length determinant }\end{array}$ \\
\hline
\end{tabular}

Table 2. The List of proteins identified by LC-MS/MS analysis of bacteriophage preparations from B. grahamii. The proteins identified by minimum two peptide matches and with statistically significant Mascot scores above threshold value indicating $95 \%$ correctly assigned peptides $(\mathrm{p} \leq 0.05)$ were included. Minimum Mascot score value of matches used in this study was 68 .

\begin{tabular}{|c|c|c|c|c|c|}
\hline Protein name & $\begin{array}{l}\text { NCBI Accession } \\
\text { Number }\end{array}$ & Protein mass/aa & Motifs/Expect & Function & $\begin{array}{l}\text { Other homologs/Accession } \\
\text { number }\end{array}$ \\
\hline $\begin{array}{l}\text { Single-strand } \\
\text { binding pro- } \\
\text { tein }\end{array}$ & YP_002972166 & $18827 / 168$ & $\begin{array}{l}\text { COG0629, Ssb, } \\
\text { Single-stranded } \\
\text { DNA-binding } \\
\text { protein/ 5e-30 }\end{array}$ & $\begin{array}{l}\text { DNA replication, recom- } \\
\text { bination, and repair }\end{array}$ & $\begin{array}{l}\text { Single-stranded DNA- } \\
\text { binding protein [Bar- } \\
\text { tonella elizabethae]/ } \\
\text { WP_005773335.1/6e-114 }\end{array}$ \\
\hline $\begin{array}{l}\text { Hemin bind- } \\
\text { ing protein c }\end{array}$ & YP_002971304 & $29756 / 277$ & $\begin{array}{l}\text { COG3637, Opac- } \\
\text { ity protein and } \\
\text { related surface } \\
\text { antigens / } 2.66 \mathrm{e}-22\end{array}$ & $\begin{array}{l}\text { Cell envelope biogenesis, } \\
\text { outer membrane }\end{array}$ & $\begin{array}{l}\text { Hemin binding pro- } \\
\text { tein C [Bartonella tribo- } \\
\text { corum CIP 105476]/ } \\
\text { YP_001608744.1/0.0 }\end{array}$ \\
\hline $\begin{array}{l}\text { Hemin bind- } \\
\text { ing protein } d\end{array}$ & YP_002971524 & $30074 / 272$ & $\begin{array}{l}\text { [COG3637], } \\
\text { Opacity protein } \\
\text { and related surface } \\
\text { antigens / 8.22e- } 25\end{array}$ & $\begin{array}{l}\text { Cell envelope biogen- } \\
\text { esis, outer membrane, } \\
\text { Bacterial surface antigens } \\
\text { expressed on the surface } \\
\text { of pathogens }\end{array}$ & $\begin{array}{l}\text { Hemin binding pro- } \\
\text { tein D [Bartonella tri- } \\
\text { bocorum CIP 105476]/ } \\
\text { YP_001609129.1/ 3e-157 }\end{array}$ \\
\hline $\begin{array}{l}\text { Hemin bind- } \\
\text { ing protein a }\end{array}$ & YP_002971305 & $30709 / 288$ & $\begin{array}{l}\text { [COG3637], } \\
\text { Opacity protein } \\
\text { and related surface } \\
\text { antigens / 8.10e- } \\
26\end{array}$ & $\begin{array}{l}\text { Cell envelope biogenesis, } \\
\text { outer membrane }\end{array}$ & $\begin{array}{l}\text { Hemin binding protein } \\
\text { a [Bartonella benselae str. } \\
\text { Houston-1]/ YP_033108/ } \\
\text { 9e-131 } \\
\text { Pap31 [Bartonella benselae } \\
\text { phage } 60457] / \text { AAC39274/ } \\
\text { 1e-128 }\end{array}$ \\
\hline $\begin{array}{l}\text { Phage protein } \\
\text { gp20 }\end{array}$ & YP_002971376 & $40394 / 358$ & $\begin{array}{l}\text { [pfam03864], } \\
\text { Phage major } \\
\text { capsid protein E/ } \\
9.14 \mathrm{e}-87\end{array}$ & $\begin{array}{l}\text { Stabilisation of the } \\
\text { condensed form of the } \\
\text { DNA molecule in phage } \\
\text { heads. }\end{array}$ & $\begin{array}{l}\text { Phage protein [Bartonella sp. } \\
\text { AR 15-3]/ CBI79567.1/0.0 }\end{array}$ \\
\hline $\begin{array}{l}\text { Phage tail } \\
\text { sheath protein } \\
\text { FI }\end{array}$ & YP_002971362 & $49305 / 463$ & $\begin{array}{l}\text { [cl01389], Phage } \\
\text { tail sheath } \\
\text { protein } / 2.43 \mathrm{e}-83\end{array}$ & Phage tail sheath & $\begin{array}{l}\text { Tail protein [Bartonella } \\
\text { doshiae]/ WP_004856878.1/ } \\
\text { WP_004856878.1/0.0 }\end{array}$ \\
\hline $\begin{array}{l}\text { Putative phage } \\
\text { portal protein }\end{array}$ & YP_002972503 & $70840 / 616$ & - & - & $\begin{array}{l}\text { Phage portal protein } \\
\text { [Bartonella elizabethae]/ } \\
\text { WP_005775294.1/0.0 }\end{array}$ \\
\hline
\end{tabular}

assisted in description of their functions and in the classification of identified bacteriophages.

The size and morphology of the phages with smaller diameter corresponds to bacteriophage-like particles occurring in Bartonella culture supernatants $[9,10]$. Nevertheless, the existence of bacteriophages with diameter $>40 \mathrm{~nm}$ was reported by Barbian and Minnick (2000) [11], who detected round to icosahedral phages with diameter $80 \mathrm{~nm}$ in B. baciliformis culture. But according to their transmission electron micrographs, particle sizes were rather heterogeneous in their sizes with diameters 40-80 nm. Likewise, the presence of bacteriophages with diameter $>40 \mathrm{~nm}$ was confirmed in BG [17] with head size in the range 50-70 nm.

Tailed phages are the most efficient gene-transfer particles developed in the process of evolution. Previous observations performed using Bartonella cultures suggested the presence of tailed bacteriophages. Umemori et al. (1992) [9] reported the presence of tailed bacteriophages with diameter $40 \mathrm{~nm}$ and short tail with length 16 nm. Furthermore, Berglund et al. (2009) [17] observed the presence of sheathed tails approximately $100 \mathrm{~nm}$ long in BG. Our proteomic analysis confirmed the presence of tail proteins with homology to viruses of family Myoviridae in both bacterial cultures. Major tail sheath protein FI identified in BH and BG bacteriophage preparations is occurring in T4-like viruses and bacteriophages P2 (Table 1 and 2). Likewise, structural protein GP20 with homology to T4 bacteriophage capsid [18] and major structural unit of contractile P2 bacteriophages phage tail tube protein FII were identified in BH culture (Table 1). Among other tail proteins confirming presence of P2-like phages were P2-like phage tail protein, P2 GPu protein functioning in tail assembly of $\lambda$-like phages and phage tail measure protein participating on phage tail assembly and determining length of phage tail. Another protein identified in BG bacteriophage preparation is putative phage portal protein (Access. No. YP_002972503) with partial 
similarity to protein gp1, which is forming bacteriophage portal vertex structure of bacteriophage P22. It has a function during membrane binding and penetration of host membrane as well as a plug holding phage DNA inside of capsid [19]. Single-strand binding proteins functioning in protection of ssDNA intermediates during DNA metabolism, were identified in both BG and $\mathrm{BH}$ bacteriophage preparations. Further large subunit of DNA packaging enzyme (gp15), several anti-repressor proteins and phage-related proteins have been found as well. Finally, another component of phage tail (gp27), baseplate (gp26, gp25), tail sheath (gp18), portal protein (gp17) and neck protein (gp13) were identified.

Bacteriophages with similar morphology to the bacteriophagelike particles and the large enveloped phages described in the current study were found in proteobacterium Pseudomonas sp. This phytopathogenic bacterium is the host of two different bacteriophages, a dsDNA bacteriophage Psp231 a belonging to the family Podoviridae (P. phaseicola, [20]) and an enveloped dsRNA bacteriophage $\Phi 6-\Phi 12$ [21,22]. The bacteriophage-like particles (diameter $42 \mathrm{~nm}$ ) are comparable to icosahedral phages Psp231a with diameter size $55 \mathrm{~nm}$ and with easily separable tails. The structure of another Cystoviridae bacteriophage $\Phi 12$ described by Wei et al (2009) which is surrounded by a lipid-containing envelope required for infectivity reminds the enveloped phage particles in our Bartonella preparations, though Bartonella bacteriophage sizes are smaller than in family Cystoviridae. This phage is able to infect not only Pseudomonas sp., however also other Gram-negative bacteria.

One of the most interesting proteins found in $\mathrm{BH}$ bacteriophage preparations is phage protein CAF27122. The protein displays significant similarity to the phage protein gp 79 having inhibitory effect on host transcription [23] or having cytotoxic effect on bacterial host [24]. These characters might be useful for development of phage therapy or study of potential drug targets against bacterial pathogens.

Functions of hemin-binding proteins and Pap31, a protein with high homology to hemin-binding protein in $\mathrm{BH}$ (99\% identity) has not been fully elucidated yet. However, common feature of these cell surface proteins is that they are conserved in several plant and animal pathogens within $\alpha$-proteobacteria [25]. Pap31 was originally considered as a phage-associated membrane protein in $\mathrm{BH}[10,26]$. But later it was suggested, that this protein is a bacteriophage receptor on the outer surface of the bacterium serving for bacterial iron acquisition [27]. Heme acquisition by Pap31 makes this protein potentially important virulence factor in the pathogenesis of $\mathrm{BH}$ [28]. Membranes of enveloped phagessuch as $\Phi 12$, fuse during the first stage of infection with bacterial outer membrane. Therefore during the process called targeted protein-dependent fusion, phage phospholipids and membrane proteins might co-purify with the bacterial outer membrane of infected cells [29].

\section{Conclusions}

Present study has shown the occurrence of bacteriophages from different families in human-pathogenic bacteria $B$. henselae and $B$. grahamii. Most of the results of our observations suggests, that B. henselae is a host of tailed dsDNA bacteriophages belonging to order Caudovirales and family Myoviridae (similar to bacteriophage P2), and enveloped bacteriophages similar to dsRNA viruses from family Cystoviridae. The Small-size bacteriophage-like parti- cles could correspond to defective or satellite phages. Similar conclusions could be drawn for B. grahamii, though less experimental evidences are available.

\section{Competing Interests}

The authors declare that they have no competing interests.

\section{Authors' Contributions}

JN performed experimental work including bacterial culture, bacteriophage isolation, SDS-PAGE and transmission electron microscopy, experimental planning and manuscript writing. MLN conducted proteomic analysis using LC-MS/MS and contributed to the manuscript writing by method description. All authors read and approved manuscript.

\section{Acknowledgement}

We would like to acknowledge Dr. Alex Mira, who has shared his experiences with Bartonellaculture and the bacteriophage isolation. We also thank to Prof. Roman Zubarev and Prof. Siv Andersson, who provided their laboratories and funding to perform this work.

\section{References}

[1]. Welch DF, Pickett DA, Slater LN, Steigerwalt AG, Brenner DJ. Rochalimea henselae sp. Nov., a cause of septicemia, bacillary angiomatosis, and parenchymal bacillary peliosis. J Clin Microbiol 1992, 30:275-280.

[2]. Adal KA, Cockeral CJ, Petri WA. Cat scratch disease, bacillary angiomatosis, and other infections due to Rochalimea. NEngl J Med 1994, 330:1509-1515.

[3]. Golnik KC, Marotto ME, Fanous MM, Heitter D, King LP, Halpern JI,Holley PH Jr. Ophthalmic manifestations of Rochalimaea species. Am J Ophthalmol 1999, 118:145-151.

[4]. Ormerod D, Skolnick KA, Menesky MM, Pavan PR, Pon DM. Retinal and choroidal manifestations of cat-scratch disease. Ophthalmology 1998, 105:1024-1031

[5]. Birtles RJ, Harrison TG, Molyneux DH. Grahamella in small woodland mammals in the U.K.: isolation prevalence and host specificity. Ann Trop Med Parasitol 1994, 888:317-327.

[6]. Kerkhoff FT, Bergmans AMC, Van der Zee A, Rothova A. Demonstration of Bartonella grahamii DNA in Ocular Fluids of a Patient with Neuroretinitis. J Clin Microbiol 1999, 37:4034-4038.

[7]. Cheethman BF, Katz ME. A role for bacteriophages in the evolution and transfer of bacterial virulence determinants. Mol Microbiol 1995, 18:201208.

[8]. Bishai WR, Murphy JR. Bacteriophages gene products that cause human disease. In The Bacteriophages. Edited by Calendar R. New York: Plenum; 1988:683-724.

[9]. Umemori E, Sasaki Y, Amano K, Amano Y. A phage in Bartonella baciliformis. Microbiol Immunol 1992, 36:731-736.

[10]. Anderson B, GoldsmithC, Johnsson A, Padmalayam I, Baumstark B. Bacteriophage-like particle of Rochalimea henselae. Mol Microbiol 1994, 13:67-73.

[11]. Barbian KD, Minnick MF: A bacteriophage particle from Bartonella baciliformis.Microbiology 2000,146:599-609.

[12]. Chenoweth MR, Somerville GA, Krause DC, O’Reilly KL, Gherardini FC. Growth characteristics of Bartonella henselae in a novel liquid medium: Primary isolation, growth-phase-dependent phage induction, and metabolic studies. Appl Environ Microbiol 2004, 70:656-663.

[13]. Anderson B, Scotchlas D, Jones D, Johnson A, Tzianabos T, Baumstartk B: Analysis of a 36-kilodalton protein (PapA) associated with the bacteriophage particle of Bartonella henselae. DNA Cell Biol 1997, 10:1223-1229.

[14]. Sambrook J, Fritsch EF, Maniatis T. Molecular Cloning: A Laboratory Manual. New York: Cold Spring Harbor Laboratory Press; 1989.

[15]. Wilm M, Shevchenko A, Houthaeve T, Breit S, Schweigerer L, Fotsis T, Mann M. Femtomole sequencing of proteins from polyacrylamide gels by nano-electrospray mass spectrometry. Nature 1996,379:466-469.

[16]. Nielsen ML, Savitski M, Zubarev R. Improving Protein Identification Using Complementary Fragmentation Techniques in Fourier Transform Mass Spectrometry. Mol Cell Proteomics 2005, 4:835-845. 
[17]. Berglund EC., Frank CA, Calteau A, Vinnere-Pettersson O, Granberg F, Eriksson AS, Näslund K, Holmberg M, Lindroos H, AnderssonSGE. RunOff Replication of Host-Adaptability Genes Is Associated with Gene Transfer Agents in the Genome of Mouse-Infecting Bartonella grahamii. PLoS Genet 2009, 5:e1000546. doi:10.1371/journal.pgen.1000546.

[18]. Liu J, Glazko G, Mushegian A. Protein repertoire of double-stranded DNA bacteriophages. Virus Res 2006, 117:68-80.

[19]. Olia AS, Bhardwaj A, Joss L, Casjens S, Cingolani G. Role of gene 10 protein in the hierarchical assembly of the bacteriophage P22 portal vertex structure. Biochemistry 2007, 46:8776-8784.

[20]. Taylor WD, DeLuca N, Vollherbst K, Doman T, D'amato T, Snipes W. Characteristics of a New Bacteriophage, Psp231a, Infecting Pseudomonas phaseolicola HB1OY. J Virol 1980, 35:918-923.

[21]. Vidaver AK, Koski RK, Van Etten JL. Bacteriophage $\Phi 6$ : a lipid-containing virus of Pseudomonasphaseolicola. J Virol 1973, 11:799-805.

[22]. Wei R, Cheng H, Berriman J, Rice WJ, Stokes DL, Katz A, Morgan DJ, Gottlieb P. Three-Dimensional Structure of the Enveloped Bacteriophage Ф12: An Incomplete $T=13$ Lattice Is Superposed on an Enclosed T=1 Shell. PLoS One 2009, 4:e6850. doi:10.1371/journal.pone.0006850.

[23]. Savalia D, Westblade LF, Goel M, Florens L, Kemp P, Akulenko N, Pavlova O, Padovan JC,. Chait BT, Washburn MP, Ackermann HW, Mushegian A, GabisoniaT, Molineux I, Severinov K. Genomic and proteomic analysis of phiEco32, a novel Escherichia coli bacteriophage. J Mol Biol 2008, 377:77489.
[24]. Rybniker J, Plum Georg G, Robinson N, Small LP, Hartmann P. Identification of three cytotoxic early proteins of mycobacteriophage L5 leading to growth inhibition in Mycobacterium smegmatis. Microbiology 2008, 154:2304-14.

[25]. Minnick MF, Sappington KN, Smitherman LS, Andersson SGE, Karlberg $\mathrm{O}$, Carroll JA. Five-Member Gene Family of Bartonella quintana. Infect Immun 2003, 71:814-821.

[26]. Bowers TJ, Sweger D, Jue D, Anderson B. Isolation, sequencing and expression of the gene encoding a major protein from the bacteriophage associated with Bartonella henselae. Gene 1998, 206:49-52.

[27]. Carroll JA, Coleman SA, Smitherman L, Minninck MF. Hemin-Binding Surface Protein from Bartonella quintana. Infect Immun 2000, 68:67506757.

[28]. Zimmermann R, Kempf VAJ, Schiltz E, Oberle K, Sander A. Hemin binding, functional expression, and complementation analysis of PAP31 from Bartonella henselae. J Bacteriol 2003, 185:1739-1744.

[29]. Bamford DH, Romantschuk M, Somerharju PJ: Membrane fusion in prokaryotes: bacteriophage phi 6 membrane fuses with the Pseudomonas syringae outer membrane. EMBOJ 1987, 5:1467-1473. 